\title{
Monosomy 1p36 syndrome: reviewing the correlation between deletion sizes and phenotypes
}

\author{
C.F. Rocha ${ }^{1}$, R.B. Vasques ${ }^{2}$, S.R. Santos ${ }^{1}$ and C.L.A. Paiva ${ }^{1,3}$ \\ ${ }^{1}$ Programa de Pós-Graduação em Neurologia, \\ Universidade Federal do Estado do Rio de Janeiro, Rio de Janeiro, RJ, Brasil \\ ${ }^{2}$ Escola de Medicina e Cirurgia, \\ Universidade Federal do Estado do Rio de Janeiro, Rio de Janeiro, RJ, Brasil \\ ${ }^{3}$ Programa de Pós-Graduação em Biologia Molecular e Celular, \\ Universidade Federal do Estado do Rio de Janeiro, Rio de Janeiro, RJ, Brasil \\ Corresponding author: C.L.A. Paiva \\ E-mail: clapaiva1@gmail.com
}

Genet. Mol. Res. 15 (1): gmr.15017942

Received October 28, 2015

Accepted December 10, 2015

Published February 19, 2016

DOI http://dx.doi.org/10.4238/gmr.15017942

\begin{abstract}
The major clinical features of monosomy $1 \mathrm{p} 36$ deletion are developmental delay and hypotonia associated with short stature and craniofacial dysmorphisms. The objective of this study was to review the cases of 1 p36 deletion that was reported between 1999 and 2014, in order to identify a possible correlation between the size of the 1 p36-deleted segment and the clinical phenotype of the disease. Scientific articles published in the (National Center for Biotechnology Information; NCBI http://www.ncbi.nlm. nih.gov/pubmed) and Scientific Electronic Library Online (www.scielo.com. br) databases were searched using key word combinations, such as "1p36 deletion", "monosomy 1p36 deletion", and "1p36 deletion syndrome". Articles in English or Spanish reporting the correlation between deletion sizes and the respective clinical phenotypes were retrieved, while letters, reviews, guidelines, and studies with mouse models were excluded. Among the 746 retrieved articles, only 17 (12 case reports and 5 series of cases), comprising
\end{abstract}


29 patients ( 9 males and 20 females, aged 0 months (neonate) to 22 years) bearing the $1 \mathrm{p} 36$ deletions and whose clinical phenotypes were described, met the inclusion criteria. The genotype-phenotype correlation in monosomy $1 p 36$ is a challenge because of the variability in the size of the deleted segment, as well as in the clinical manifestations of similar size deletions. Therefore, the severity of the clinical features was not always associated with the deletion size, possibly because of the other influences, such as stochastic factors, epigenetic events, or reduced penetration of the deleted genes.

Key words: Monosomy 1 p36 syndrome; 1 p36 deletion syndrome; Deletion size; Phenotype

\section{INTRODUCTION}

Monosomy $1 \mathrm{p} 36$, or the $1 \mathrm{p} 36$ deletion syndrome, is a subtelomeric monosomy with an incidence of 1 in every 5000 births. A majority of the cases (52-67\%) have a terminal deletion on chromosome 1. Interstitial deletions (9.7-29\%) and other abnormalities, such as derivative chromosomes (7$16.4 \%$ ) and complex rearrangements, are less frequent (Shiba et al., 2013; Õiglane-Shlik et al., 2014).

The major clinical features of 1 p36 deletion syndrome include motor developmental delay and hypotonia associated with short stature and craniofacial dysmorphisms, such as large anterior fontanel, prominent forehead and chin, deep eyes, a flat nasal bridge, maxillary hypoplasia, and ear asymmetry (Zagalo et al., 2012). The patients may also show skeletal malformations, cardiac, gastrointestinal, and visual abnormalities, seizures, and behavioral disorders.

Monosomy 1 p36 is the most common terminal deletion in human beings, responsible for about $1 \%$ of all cases of idiopathic mental retardation (Battaglia et al., 2008). Therefore, the objective of this paper was to review the cases of $1 \mathrm{p} 36$ deletion syndrome described in the literature from 1999 to 2014 , and to correlate the size of the 1p36-deleted segments with the clinical phenotypes.

\section{MATERIAL AND METHODS}

The scientific articles submitted to the database at the National Center for Biotechnology Information (NCBI; http://www.ncbi.nlm.nih.gov/pubmed) and the Scientific Electronic Library Online (www.scielo.com.br) websites were electronically searched using various combinations of key words, including "1p36 deletion", "monosomy 1p36 deletion", and "1p36 deletion syndrome".

Articles published between 1999 and 2014, written in English or Spanish, which reported an association between the size of the deletion in each patient and their respective clinical phenotypes, were retrieved. Articles showing an association with the phenotype while excluding the measurement of the size of the deletion were excluded from this review; additionally, those papers reporting changes on chromosomes other than chromosome 1p36 were also excluded. Letters, reviews, guidelines, and studies in mouse models were also excluded.

\section{RESULTS}

The search retrieved 746 articles. Among these, 17 scientific articles met the criteria for inclusion and were selected for this study (D'Angelo et al., 2006; Krepischi-Santos et al., 2006; Kang et al., 2007; Robinson et al., 2008; Bursztejn et al., 2009; El-Hattab et al., 2010; Gajecka 
et al., 2010; Rosenfeld et al., 2010; Haimi et al., 2011; Mikhail et al., 2011; Nicoulaz et al., 2011; Giannikou et al., 2012; Gervasini et al., 2013; Shiba et al., 2013; Zhu et al., 2013; Shimada et al., 2014; Stagi et al., 2014). Among these, 12 were case reports and five reported series of cases. These articles included a total of 29 patients ( 9 males and 20 females aged 0 months (neonate) to 22 years) bearing the measured 1 p36 deletions, and whose clinical phenotypes have been described. The deletion sizes ranged from $199 \mathrm{~kb}$ to $16 \mathrm{Mb}$.

All deletions and phenotypes are indicated in an ideogram of chromosome 1, with an amplified 1p36.11-1p36.33 region (Figure 1). Developmental delay, especially psychomotor delay $(44.82 \%)$, was prominently observed. Additionally, the articles reported various neurological manifestations, such as failure in oral expression $(55.17 \%)$, hypotonia $(48.27 \%)$, intellectual disability $(48.27 \%)$, and epilepsy (41.37\%), among others.

\section{DISCUSSION}

In this study, we selected 17 articles reporting a deletion in chromosome 1 (1p36). The majority of the patients analyzed in these articles were females, a finding that has been previously reported (Slavotinek et al., 1999).

Various techniques are employed to detect chromosomal deletions; array comparative genome hybridization $(\mathrm{aCGH})$ is a technique that covers the whole genome. This technique is more effective than the multiplex ligation probe amplification (MLPA) method, used to detect other chromosomal alterations when 1 p36 deletion was not clinically suspected (D'Angelo et al., 2010). The aCGH method can also be used to determine the break points and measure the size of chromosomal loss (Battaglia et al., 2008), allowing the investigation of genotype-phenotype association.

Another technique used to identify chromosomal deletions is conventional or high-resolution karyotype analysis; however, these methods are often unable to detect small changes in the 1p36 segment, as it is a clear G-band on the tip of the terminal region of the short arm of chromosome 1 (Slavotinek et al., 1999); moreover, deletions smaller than 2-3 Mb are not visible with common optical microscopy. Fluorescence in situ hybridization (FISH), as well as some other techniques, can be used to complement the cytogenetic study, confirming a partial monosomy in metaphases and/or interphases. FISH can be used to confirm the microdeletion, discovered using other methods such as CGH array or MLPA, when the karyotype is normal and when there is a strong clinical suspicion of the syndrome.

Cunha et al. (2014) also described a technique, using real-time quantitative PCR with a sensitivity and specificity of $100 \%$, for the detection of monosomy $1 \mathrm{p} 36$. This technique was validated in two genes, PRKCZ and SKI, which were absent in most of their patients: eight of the patients $(8 / 29)$ presented these deleted genes.

The deletion size can be used to explain the clinical variability of phenotypes such as the ones observed in other structural chromosomal syndromes (Gajecka et al., 2007). Deletions ranging from $199 \mathrm{~kb}$ to $16 \mathrm{Mb}$ have been previously reported (Rosenfeld et al., 2010; Nicoulaz et al., 2011). Patients bearing 1p36 deletions of different sizes have been shown to express similar phenotypes. This indicated that the final aspect of the syndrome is governed by more complex causes than a simple contiguous gene deletion (Õiglane-Shlik et al., 2014) (Figure 1), such as the effect of the position of one or more genes, genetic and/or environmental factors that may aggravate or mitigate the phenotype, and copy number variations or other genetic mutations other than 1p36. For example, Õiglane-Shlik et al. (2014) reported that only one of four patients with the same deletion on 1p36 presented congenital heart defect, seizures, and behavioral changes. 


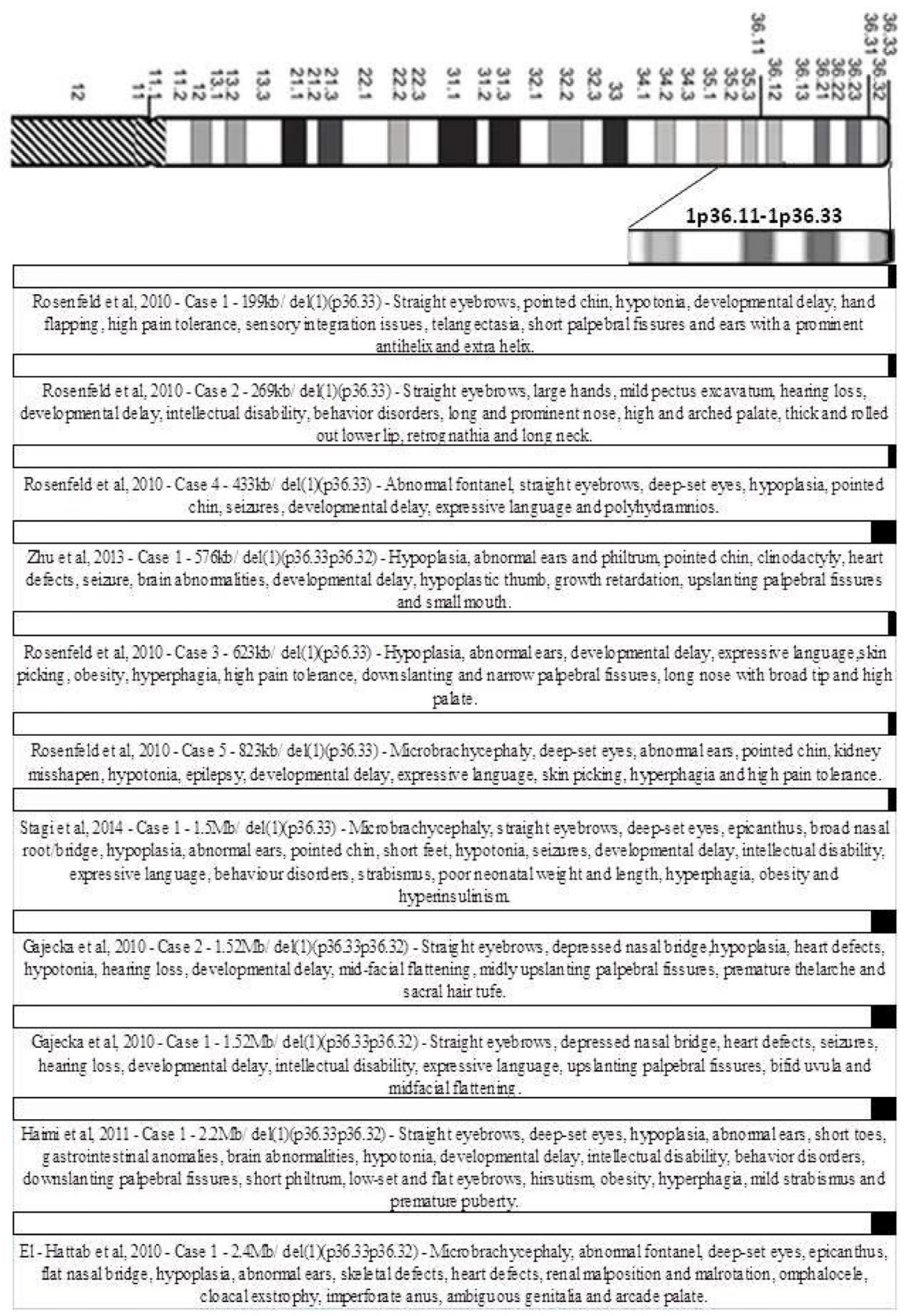

Figure 1. Ideogram of the short arm of chromosome 1, and the amplified 1p36.11-1p36.33 region, depicting the different deleted bands and their respective clinical aspects.

Continued on next page 
Figure 1. Continued

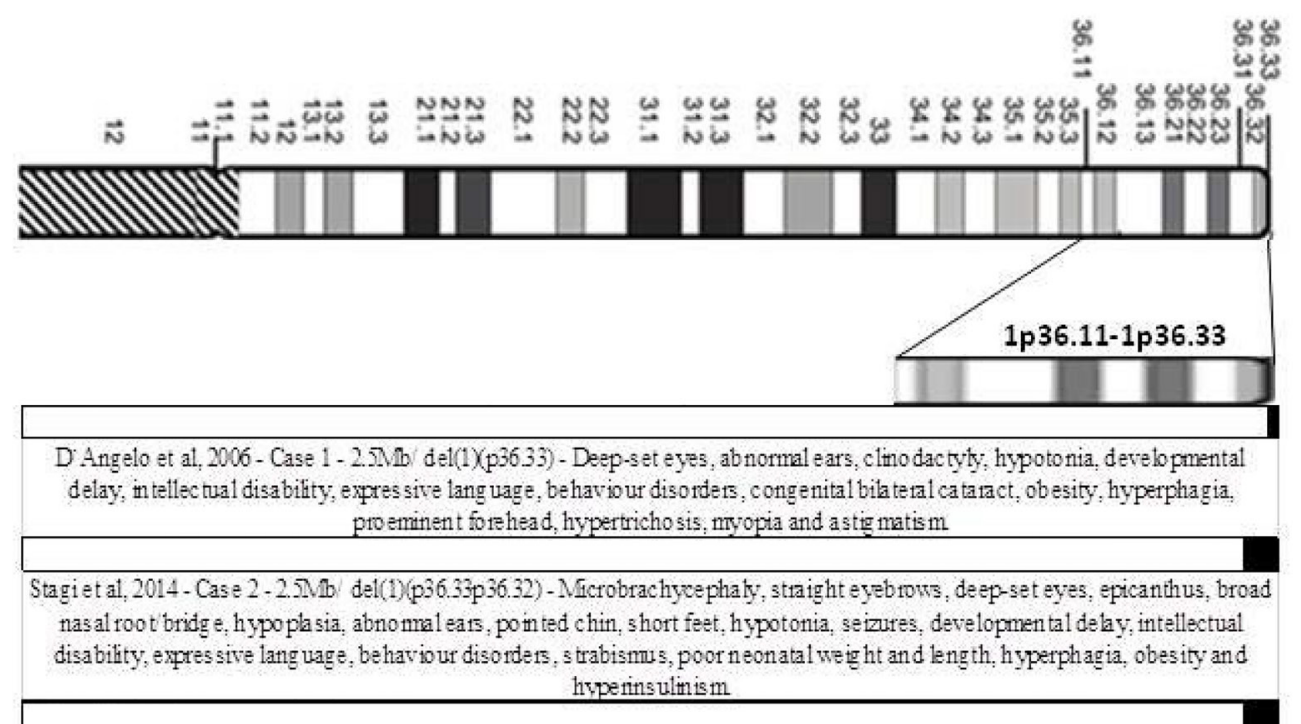

Shimada et a1, 2014 - Case 1 - 3Mb/del(1)(p36.33p36.32) - Deep-set eyes, epicanthus, broad nasal toot, abnormal philtum pointed chin, heart defects, hypo ton ia developmental delay, in tellectual dis ability, expres sive lang uag e, obesity; sle ep apnea and skin hyperpigmentation. and depig mentation.

Shimada et al 2014 - Case $2-4.5 \mathrm{Mb}$ del(1)(p36.33p36.32) - Abnormal fon tanel, straight eyebrows, pointed chin, developmenta1 delay, expressive hnguage, behaviour disordets, apnea, obesity, strabismns, astigmatismand hypermetropia

Robinson et al, 2008 - Case 1-5.JMb del(1)(p36.3) - Epicanthus, abnomal eats, dorsiflexion of the halux heart defect, vesicoureteral reflux, brain abnoma litties, hearing los s, deve bopment tal delay, intellectual disability, prenatal growth retardation, hig $h$ forehead, bilateralptosis, blepharophimosis, thin lips and immature te tinas.

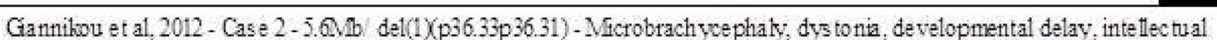
disability, expressive language, arched upper lip, short antmongoloid pa pebral features and big promiment forehead uth medium blink.

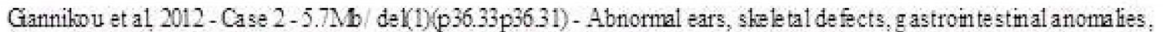
developmental delay, intellec tual disability, expres sive lang uag e, triangular facies, arched palate, long nose, thick eyebrows and short neck

Kang et a1, 2007 - Case 5-9.4.Mb del(1)(p36.2p36.3) - Microbrachyce phaly, straight eyebrows, hypopla sia, abnormal ears, pointed chin, heat defects, hypotonia, seizres, developmental delay, expessive language, hypertelorism anteverted nares, growth retardation and hirsutism

Nicoulazet a1, 2011 - Case 1-16M/ del(1)(p36.33p36.13) - Deep-set eyes, abnomal ears, ponted chin, shele tal defects, gas trointestinal anomatlies, he att defects, brain abnomalities, polyhydamnion, increas ed tuchal translucency; small palpebral fissures and prenatal growth retardation.

Mithailet al, 2011 - Case 3 - 305tb/ del(1)(p36.31) - Abnoma la taxic gait, developmental delay; intellec tual disa bility, expres sive language and hpperactivity

Kang et a1, 2007-Case 1-2.5Mb del(1)(p36.12p36.2) - Mcrobrachycephaly, epicanthus, abnomal ears, pointed chin, heart defects, seizure, hypotonia, developmental delay, anteverted nares and g rowth retardation. 
Figure 1. Continued

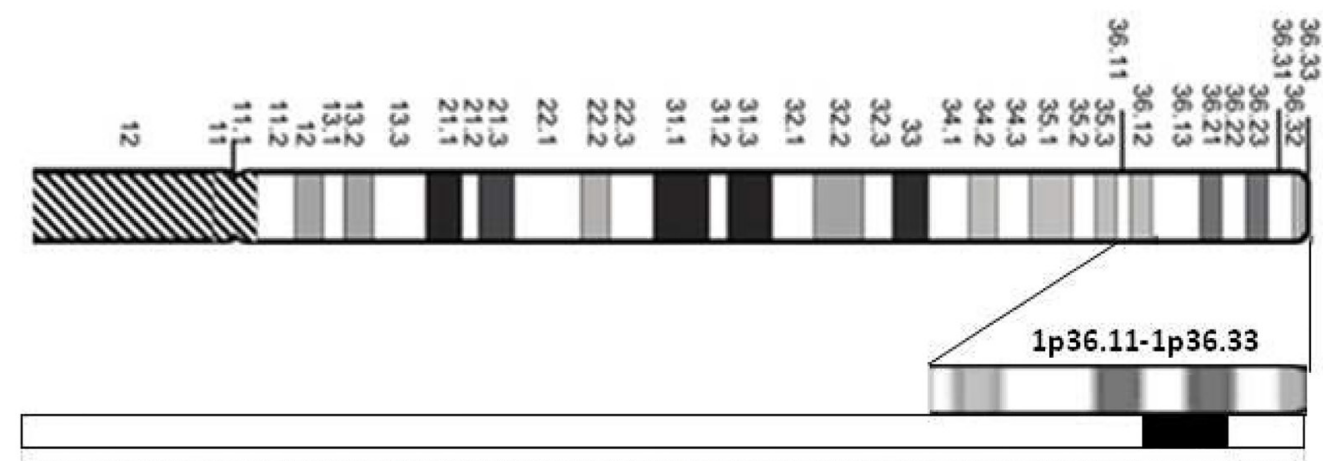

Kang et at, 2007 - Case 4-2.9Mb del(1)(p36.22p 36.23) - Straight eyeb rows, epican thus, abnormal ears, clinodactyly, heart defects, hypotonia, developmental d elay, expressive language, anteverted nares, high arcad e palate, grow th retardation and hisutism.

Krepischi-Santos et a1, 2006-Case $1-3.3 \mathrm{Mb}$ del(1)(p36.32) - Depressed nasal bridge, hypoplas ia, clinodactyly, heart defects, seizutes, developmental delay, growth te tatda tion, dolichocephaly, hypertelorism coloboma of the right itis and coroid: macrostomia, microg nathia, hypoplasia of the labia monora and anteriorly displaced anus.

Gerv asini et at 2013 - Case $1-4.8 \mathrm{M}$ del(1)(p36.23 3622$)$ - Mcrobrachycephaly, s traight eye brows, abno mal philtrum, small hands, proximally places thumb and slight toenail dys plasia, gas trointestinal anomalies, heart de fects, neurological findings: developmental delay, intellec tual dis ability, hyperac tivity, large mou th, thin upper lip, microgna thia and antevented nates.

\begin{tabular}{|c|c|}
\hline & 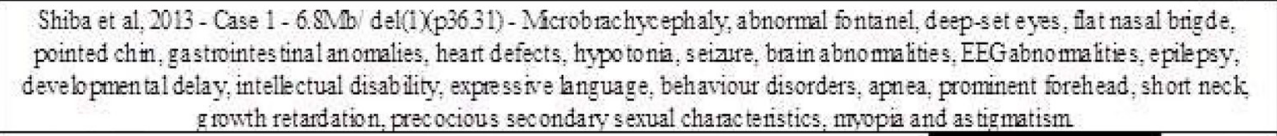 \\
\hline & $\begin{array}{l}\text { Kang et al, } 2007 \text {-Case } 2-11.4 \mathrm{Mb} \text { del(1)(p36.11p36.22)-Microbrachycephaly, straight eyebrous, epicanthus, hypoplasia, } \\
\text { abnormal ears, clinodactyly, heart defects, hypotonia, seizres, developmental delay, expressive language, hyperte brism, } \\
\text { anteverted trates, g towth retardation and hirsutism }\end{array}$ \\
\hline & $\begin{array}{c}\text { Burstejn et at, } 2009 \text { - Case } 1-11.73 \mathrm{Mb} \text { del(1)(p36.22) - Deep-set eyes, abnormal ears, brachydactyly, heart defects, seizure, EEG } \\
\text { abnomalites, brain abnormalities, developmental delay, in tellectual disability and hypertricho sis. }\end{array}$ \\
\hline & 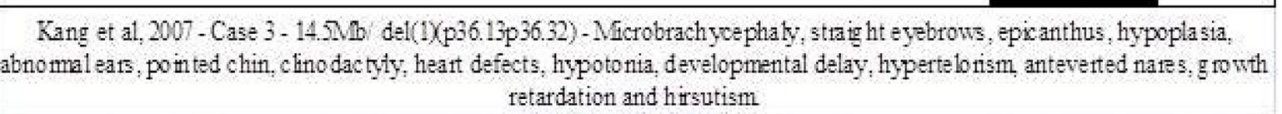 \\
\hline
\end{tabular}

On the other hand, Rosenfeld et al. (2010) reported a deletion in the GABRD gene, which encodes the delta subunit of the gamma-amino butyric acid $(G A B A)_{A}$ receptors, in three $1 \mathrm{p} 36$ deletion patients. GABA is the major inhibitory neurotransmitter in the mammalian brain where it acts at $\mathrm{GABA}_{A}$. Mutations in this gene have been associated with susceptibility to generalized epilepsy with febrile seizures. Two of the three patients also presented convulsive frames. This could be explained by mechanisms such as stochastic factors, epigenetic factors, and/or the lack of complete penetrance of the gene, which could influence the clinical picture and avoid the precise phenotype-genotype correlation.

One possible explanation for the emergence of deletions causing monosomy 1 p36 is the 
presence of repetitive DNA sequence elements that can generate and/or stabilize these deletions.

The presence of mosaicism in 1p36 deletion has also been described in two patients with developmental delay, syndromic facies, obesity, and mild neurological disabilities. These mosaic individuals did not present speech disabilities and could walk without help, features that are milder compared to those shown by patients with the typical deletion (Shimada et al., 2014).

The most prevalent clinical feature observed in the patients analyzed in this review was developmental delay (psychomotor, motor, or global); this was followed by neurological disorders, such as hypotonia, epilepsy, brain malformation, hearing loss, dystonia, and ataxic gait. The protooncogene SKI, involved in myelination and the development of Schwann cells (Atanasoski et al., 2004), was one of the deleted genes; the CAMTA1 gene, which encodes a member of the transcription activator family connected to calmodulin, expressed in some regions of the brain involved with embryo development and growth control (Finkler et al., 2007) also expressed deletions. The other genes implicated in neurological development are GNB1, associated with the size of the brain; TP73, connected to brain malformation; and $G A B R D$, which plays a role in the development of seizures.

Patients with partial monosomy are at a greater risk of developing neoplasms, although this does not always occur. It is noteworthy that the suppression of other candidate genes for cancer susceptibility located in the same region, such as the CDC2L2, TNFRSF25, AJAP1, TP73, CAMTA1, may also contribute to the development of malignancies.

In this review, we identified 17 patients with cardiac anomalies, such as ventricular septal defect, persistence of the arterial duct, atrial septal defect, cardiac enlargement, defective mitral valve, changes in deployment of the pulmonary vein, and puff, among others. These abnormalities are commonly found in monosomy 1p36. Deletions in the SKI (Rosenfeld et al., 2010) or PRDM16 genes can lead to cardiomegaly, which is the most common abnormality found in patients according to the literature (Slavotinek et al., 1999). However, only one of the patients included in this review presented a deleted SKI gene and cardiomegaly. In addition to these genes, region 1 p36.22 has at least 23 known genes, many of which are expressed in the heart (Kang et al., 2007).

Several clinical features of monosomy 1p36, such as overeating, obesity, hypotonia, cognitive deficits and psychomotor delay, overlap with those of Prader-Willi syndrome (PWS). Patients showing the PW phenotype, but who present a negative result when tested for PWS, were believed to express a Prader-Willi-like phenotype. Therefore, monosomy $1 \mathrm{p} 36$ should also be investigated in Prader-Willi-like patients. Not only 1 p36 deletion symptoms overlap with those of PWS, but also the symptoms of various other syndromes and chromosomal abnormalities overlap with PWS (Rocha and Paiva, 2014). Here, we identified four cases of monosomy 1 p36 showing the Prader-Willi-like phenotype. According to Tsuyusaki et al. (2010), such a phenotype is associated with the 4-Mb 1p36 terminal deletion.

Even small deletions in 1p36 monosomy have been shown to lead to phenotypic alterations; the patient expressing the smallest deletion described in this review (199 kb) presented phenotypes such as straight eyebrows, pointed chin, hypotonia, developmental delay, intellectual and behavioral changes, high tolerance to pain, short palpebral fissure, telangectasia, and pinna abnormalities (Rosenfeld et al., 2010). On the other hand, the patient showing the largest chromosomal loss (16 $\mathrm{Mb}$ ) featured deep eyes, skeletal, gastrointestinal, cardiac and cerebral abnormalities, prenatal growth delay, polyhydramnios, and increased nuchal translucency (Nicoulaz et al., 2011).

The genotype-phenotype correlation in monosomy 1 p36 syndrome is a challenge because of the variability in the size of the deleted segment, as well as in the clinical manifestations, which were not always related to the size of the deleted chromosome. In addition, the severity of the clinical 
pictures were not always associated with the deletion size, probably because of other influences such as, stochastic factors, epigenetic events, or reduced penetration of the deleted genes.

\title{
Conflicts of interest
}

The authors declare no conflict of interest.

\section{ACKNOWLEDGMENTS}

\author{
Research supported by Coordenação de Aperfeiçoamento de Pessoal do Ensino Superior \\ (CAPES), Universidade Federal do Estado do Rio de Janeiro (UNIRIO), and Financiadora de \\ Estudos e Projetos (FINEP).
}

\section{REFERENCES}

Atanasoski S, Notterpek L, Lee HY, Castagner F, et al. (2004). The protooncogene Ski controls Schwann cell proliferation and myelination. Neuron 43: 499-511. http://dx.doi.org/10.1016/j.neuron.2004.08.001

Battaglia A, Hoyme HE, Dallapiccola B, Zackai E, et al. (2008). Further delineation of deletion 1 p36 syndrome in 60 patients: a recognizable phenotype and common cause of developmental delay and mental retardation. Pediatrics 121: 404-410. http://dx.doi.org/10.1542/peds.2007-0929

Bursztejn AC, Bronner M, Peudenier S, Grégoire MJ, et al. (2009). Molecular characterization of a monosomy 1 p36 presenting as an Aicardi syndrome phenocopy. Am. J. Med. Genet. A. 149A: 2493-2500. http://dx.doi.org/10.1002/ajmg.a.33051

Cunha PdaS, Pena HB, D'Angelo CS, Koiffmann CP, et al. (2014). Accurate, fast and cost-effective diagnostic test for monosomy 1 p36 using real-time quantitative PCR. Dis. Markers 2014: 836082. http://dx.doi.org/10.1155/2014/836082

D'Angelo CS, Da Paz JA, Kim CA, Bertola DR, et al. (2006). Prader-Willi-like phenotype: investigation of 1 p36 deletion in 41 patients with delayed psychomotor development, hypotonia, obesity and/or hyperphagia, learning disabilities and behavioral problems. Eur. J. Med. Genet. 49: 451-460. http://dx.doi.org/10.1016/i.ejmg.2006.02.001

D'Angelo CS, Kohl I, Varela MC, de Castro Cl, et al. (2010). Extending the phenotype of monosomy $1 \mathrm{p} 36$ syndrome and mapping of a critical region for obesity and hyperphagia. Am. J. Med. Genet. A. 152A: 102-110. http://dx.doi.org/10.1002/ ajmg.a.33160

El-Hattab AW, Skorupski JC, Hsieh MH, Breman AM, et al. (2010). OEIS complex associated with chromosome 1 p36 deletion: a case report and review. Am. J. Med. Genet. A. 152A: 504-511. http://dx.doi.org/10.1002/ajmg.a.33226

Finkler A, Ashery-Padan R and Fromm H (2007). CAMTAs: calmodulin-binding transcription activators from plants to human. FEBS Lett. 581: 3893-3898. http://dx.doi.org/10.1016/j.febslet.2007.07.051

Gajecka M, Mackay KL and Shaffer LG (2007). Monosomy 1 p36 deletion syndrome. Am. J. Med. Genet. C. Semin. Med. Genet. 145C: 346-356. http://dx.doi.org/10.1002/ajmg.c.30154

Gajecka M, Saitta SC, Gentles AJ, Campbell L, et al. (2010). Recurrent interstitial 1p36 deletions: Evidence for germline mosaicism and complex rearrangement breakpoints. Am. J. Med. Genet. A. 152A: 3074-3083. http://dx.doi.org/10.1002/ ajmg.a. 33733

Gervasini C, Picinelli C, Azzollini J, Rusconi D, et al. (2013). Genomic imbalances in patients with a clinical presentation in the spectrum of Cornelia de Lange syndrome. BMC Med. Genet. 14: 41. http://dx.doi.org/10.1186/1471-2350-14-41

Giannikou K, Fryssira H, Oikonomakis V, Syrmou A, et al. (2012). Further delineation of novel 1p36 rearrangements by arrayCGH analysis: narrowing the breakpoints and clarifying the "extended" phenotype. Gene 506: 360-368. http://dx.doi. org/10.1016/j.gene.2012.06.060

Haimi M, lancu TC, Shaffer LG and Lerner A (2011). Severe lysosomal storage disease of liver in del(1)(p36): a new presentation. Eur. J. Med. Genet. 54: 209-213. http://dx.doi.org/10.1016/j.ejmg.2010.11.012

Kang SH, Scheffer A, Ou Z, Li J, et al. (2007). Identification of proximal 1p36 deletions using array-CGH: a possible new syndrome. Clin. Genet. 72: 329-338. http://dx.doi.org/10.1111/j.1399-0004.2007.00876.x

Krepischi-Santos AC, Vianna-Morgante AM, Jehee FS, Passos-Bueno MR, et al. (2006). Whole-genome array-CGH screening in undiagnosed syndromic patients: old syndromes revisited and new alterations. Cytogenet. Genome Res. 115: 254-261. http://dx.doi.org/10.1159/000095922

Mikhail FM, Lose EJ, Robin NH, Descartes MD, et al. (2011). Clinically relevant single gene or intragenic deletions encompassing 
critical neurodevelopmental genes in patients with developmental delay, mental retardation, and/or autism spectrum disorders. Am. J. Med. Genet. A. 155A: 2386-2396. http://dx.doi.org/10.1002/ajmg.a.34177

Nicoulaz A, Rubi F, Lieder L, Wolf R, et al. (2011). Contiguous $\sim 16 \mathrm{Mb} 1 \mathrm{p} 36$ deletion: Dominant features of classical distal 1 p36 monosomy with haplo-lethality. Am. J. Med. Genet. A. 155A: 1964-1968. http://dx.doi.org/10.1002/ajmg.a.33210

Õiglane-Shlik E, Puusepp S, Talvik I, Vaher U, et al. (2014). Monosomy 1 p36 - a multifaceted and still enigmatic syndrome: four clinically diverse cases with shared white matter abnormalities. Eur. J. Paediatr. Neurol. 18: 338-346. http://dx.doi. org/10.1016/j.ejpn.2014.01.008

Robinson DM, Meagher CC, Orlowski CC, Lagoe EC, et al. (2008). Young-Simpson syndrome (YSS), a variant of del(1)(p36) syndrome? Am. J. Med. Genet. A. 146A: 1571-1574. http://dx.doi.org/10.1002/ajmg.a.32096

Rocha CF and Paiva CLA (2014). Prader-Willi-like phenotypes: a systematic review of their chromosomal abnormalities. Genet. Mol. Res. 13: 2290-2298. http://dx.doi.org/10.4238/2014.March.31.9

Rosenfeld JA, Crolla JA, Tomkins S, Bader P, et al. (2010). Refinement of causative genes in monosomy 1p36 through clinical and molecular cytogenetic characterization of small interstitial deletions. Am. J. Med. Genet. A. 152A: 1951-1959. http:// dx.doi.org/10.1002/ajmg.a.33516

Shiba N, Daza RA, Shaffer LG, Barkovich AJ, et al. (2013). Neuropathology of brain and spinal malformations in a case of monosomy 1p36. Acta Neuropathol. Commun. 1: 45. http://dx.doi.org/10.1186/2051-5960-1-45

Shimada S, Maegaki Y, Osawa M and Yamamoto T (2014). Mild developmental delay and obesity in two patients with mosaic 1 p36 deletion syndrome. Am. J. Med. Genet. A. 164A: 415-420. http://dx.doi.org/10.1002/ajmg.a.36304

Slavotinek A, Shaffer LG and Shapira SK (1999). Monosomy 1p36. J. Med. Genet. 36: 657-663.

Stagi S, Lapi E, Pantaleo M, Chiarelli F, et al. (2014). Type II diabetes and impaired glucose tolerance due to severe hyperinsulinism in patients with 1 p36 deletion syndrome and a Prader-Willi-like phenotype. BMC Med. Genet. $15: 16$. http://dx.doi.org/10.1186/1471-2350-15-16

Tsuyusaki Y, Yoshihashi H, Furuya N, Adachi M, et al. (2010). 1p36 deletion syndrome associated with Prader-Willi-like phenotype. Pediatr. Int. 52: 547-550. http://dx.doi.org/10.1111/j.1442-200X.2010.03090.x

Zagalo A, Dias P, Pereira C and Sampaio MdeL (2012). Morbid obesity in a child with monosomy 1 p36 syndrome. BMJ Case Rep. 2012: 2012. http://dx.doi.org/10.1136/bcr.01.2012.5503

Zhu X, Zhang Y, Wang J, Yang JF, et al. (2013). 576 kb deletion in 1p36.33-p36.32 containing SKI is associated with limb malformation, congenital heart disease and epilepsy. Gene 528: 352-355. http://dx.doi.org/10.1016/j.gene.2013.07.024 